\title{
EVALUATION OF FLAT SHALLOW CAVITY SOLAR COLLECTOR INSERTED WITH POROUS LAYER
}

Karima Esmail Amori

Drkarima63@gmail.com

University of Baghdad -College of Engineering- Mechanical Engineering Department

\begin{abstract}
The evaluation of flat shallow cavity solar collector inserted with porous substrate was investigated experimentally and numerically. The aim of this work is to improve the thermal performance of flat plate solar collectors using enhanced heat transfer technique. Porous media were made of multilayer of aluminum mesh to form a porous layer of thickness $25 \mathrm{~mm}$ inserted under the absorber plate with porosity of 0.9 and permeability of 84.87 . The solar collector was installed in Baghdad south facing at a fixed tilt angle $\left(45^{\circ}\right)$. Three types of solar collector have been designed and constructed namely solar collector made of shallow enclosure (model I), solar collector made of shallow enclosure inserted partially with porous layer (model II) and solar collector with channels of corrugated channels inserted partially with porous layer (model III). The results of parametric study of model III in case of continuous operating showed that the maximum average water temperature difference of water between collector outlet and inlet exceeds $\left(7.21^{\circ} \mathrm{C}\right)$ and the maximum outlet temperature exceeds $\left(50^{\circ} \mathrm{C}\right)$ at solar noon for (November, and December 2013). The thermal efficiency for collector model III was ranged from $47.52 \%$ to $52.2 \%$, while that for model I was ranged $(33.5 \%$ to $42.3 \%)$ under the same environmental conditions.
\end{abstract}

Key words: flat plate collector, thermosyphon system, loss coefficient, efficiency.

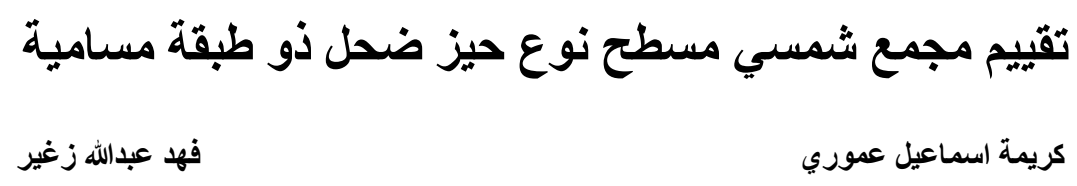

الخلاصة

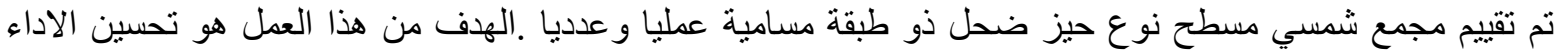

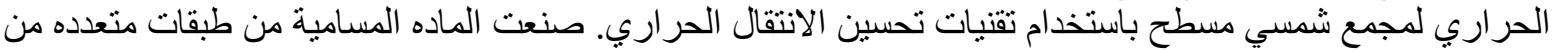

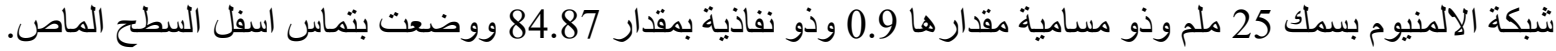

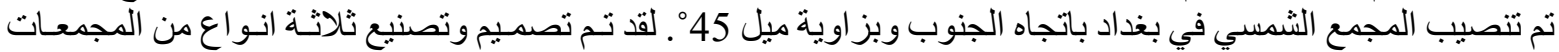

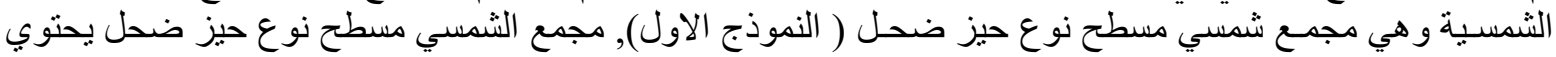

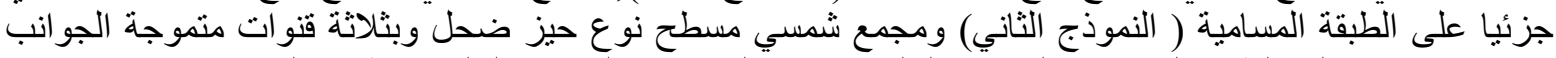

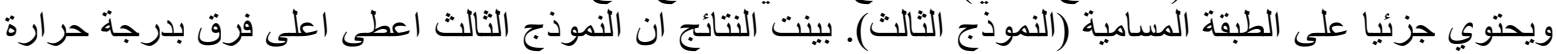

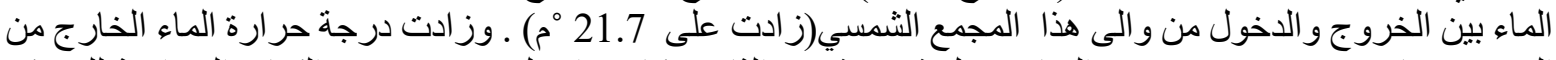

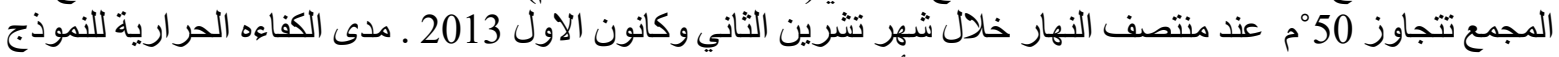

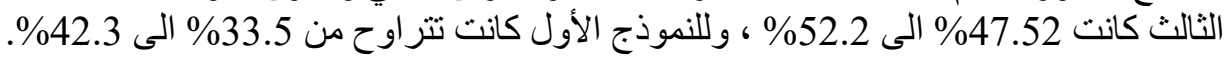




\section{Symbol Definition}

$\begin{array}{cl}\text { A } & \text { Area of solar collector }\left(\mathrm{m}^{2}\right) \\ \mathrm{Cp} & \text { specific heat }(\mathrm{J} / \mathrm{kg} . \mathrm{k}) \\ \mathrm{F}_{\mathrm{R}} & \text { Heat removal factor } \\ \mathrm{F}^{\prime} & \text { Collector efficiency factor } \\ \mathrm{F}^{\prime \prime} & \text { Collector flow factor } \\ \mathrm{G} & \text { Gravitational acceleration }\left(\mathrm{m} / \mathrm{s}^{2}\right) \\ \mathrm{h} & \text { Coefficient of heat transfer }\left(\mathrm{W} / \mathrm{m}^{2} . \mathrm{K}\right) \\ \mathrm{I}_{\mathrm{t}} & \text { Total incident radiation }\left(\mathrm{W} / \mathrm{m}^{2}\right) \\ \mathrm{K} & \text { Permeability } \\ \mathrm{m} & \text { Mass flow rate of water }(\mathrm{kg} . \mathrm{s}) \\ \mathrm{Nu} & \text { Nusselt number } \\ \mathrm{Q} & \text { Energy }(\mathrm{W})\end{array}$

\section{Greek Symbols}

$\begin{array}{ll}\text { A } & \text { Absorptance of absorber } \\ \beta & \text { Tilt angle (degree) } \\ \mathrm{H} & \text { efficiency } \\ \varepsilon & \text { Porosity } \\ \sigma_{k} & \text { model constant }\end{array}$

\section{Subscripts}

$\begin{array}{llll}\text { A } & \text { Ambient } & \text { m } & \text { Mean } \\ \text { B } & \text { Bottom } & \text { o } & \text { Outlet } \\ \text { C } & \text { Convection } & \text { p } & \text { Plate } \\ \text { E } & \text { Edge, or effective } & \text { r } & \text { Radiation } \\ \text { F } & \text { Fluid } & \text { s } & \text { Solid } \\ \text { G } & \text { Glass } & \text { sf } & \text { Solid-fluid interface } \\ \text { I } & \text { Inlet } & \text { u } & \text { Useful } \\ & & \text { w } & \text { Water }\end{array}$

\section{INTRODUCTION}

Energy consumption in providing hot water comprises an important fraction of the total worldwide energy consumption (Suarez et al. 2009). Heating and domestic water production represent $50-75 \%$ of the energy consumption of the residential sector, according to the climate (Motte et al. 2013). Solar thermal collectors are one suitable tools for cleanly providing houses with that needed energy. The incorporation of solar thermal collectors or photovoltaic (PV) panels to decrease fossil energy consumption in the residential sector is becoming more common every day [Chow et.al. 2009]. Most thermal collectors consist of a 
flat plate of approximately $2 \mathrm{~m}^{2}$ that is placed on the building's roof for low temperature applications $30-70^{\circ} \mathrm{C}$ and/or for applications that require heat during the winter months.

(Chiou 1982) developed analytical model for determination of the deterioration of thermal performance of flat plate solar collector due to flow no uniformity in the risers. $\mathrm{He}$ found that the deterioration of the collector efficiency becomes quite significant if some tubes are completely plugged up. Also a relationship is found between the deterioration of the collector efficiency and flow no uniformity parameter. (Hassab et al. 1987) investigated a flat plate solar air collector in which air flows perpendicularly from the transparent cover to the porous absorber plate. This collector is designed such that no natural convective currents take place under various system parameters. The results indicate that the best operating efficiency can be obtained when running the collector with a mass flow rate of $\dot{m}>40 \mathrm{~kg} / \mathrm{m} . \mathrm{h}$.

(Zerrouki, et.al. 2002) presented an analysis of natural circulation of a compact thermosyphon solar domestic hot water (SDHW) system produced and commercialized locally in Algeria. Calculations and measurements were performed on the mass flow rate, temperature rise of fluid and absorber temperatures inside the thermosyphon of parallel tube design. (Chen and Liu 2004) studied numerically heat transfer and air flow in a composite wall solar collector system with a porous absorber. They used this collector as a thermal insulator when sunlight is not available and as an air header during day. The effect of porous layer thickness on air temperature inside the heater room has been investigated. They found the space temperature reaches $27{ }^{\circ} \mathrm{C}$ for wall porosity of $0.25 \%$ when the outside average temperature was $10{ }^{\circ} \mathrm{C}$ and maximum solar radiation was $350 \mathrm{~W} / \mathrm{m}^{2}$. (Yousef 2008) studied theoretically the effect of mass flow rate, flow channel depth and collector length on the system thermal performance and pressure drop through the collector with and without porous medium. The solution procedure is performed for flat plate collector in single and double flow mode. The results show that the system thermal efficiency increases by $10-12 \%$ in double flow mode than single flow due to the increase in heat removal, by $8 \%$ after using porous medium in the lower channel as a result of the increase of heat transfer area. At the same time the pressure drop is increased also. (Sekhar et.al. 2009) evaluated the top loss coefficient of single glass cover flat plate collector both theoretically and experimentally under laboratory conditions. He concluded that the emissivity of the absorber plate has a significant impact on the top loss coefficient and consequently on the efficiency of the flat plate collector. The efficiency of flat plate collector is found to increase with increasing ambient temperature. There is no significant impact of tilt angle on the top loss coefficient.

The aim of this work is to investigate the effect of inserting a porous layer in shallow cavity solar collector after designing, manufacturing and instrumenting three types of solar collectors.. The contribution of the present work is to investigate a collector with wavy channels inserted with porous layer. Develop and solve a mathematical model of the adopted design, with the the adopted design, with the appropriate boundary conditions and interface condition utilizing FLUENT software and specify the effect of using this new type collector on the thermal performance of solar water heating system for Iraq climate conditions.

\section{THEORETICAL AND NUMERICAL MODEL}

Computation of fluid flow and heat transfer of water within different solar collector model, the overall heat loss coefficient the useful heat gain, and the efficiency of the solar collector as well as the of pressure drop across the porous medium were calculated.

\section{Mathematical Model Governing differential equations}

To obtain a mathematical simulation for steady state, turbulent, natural convection heat transfer in solar collector partially filled with porous layers, several assumptions have been 
made Steady three dimensional incompressible fluid flows, all thermophysical properties of water are independent of temperature except the density, neglecting the back and edge heat loss from collectors and finally water enters the collector at uniform temperature with parabolic velocity profile.

The fluid saturated porous medium is considered in local thermal non equilibrium, i.e. the energy transport is based on the twophase equation model. A key modeling equations in FLUENT for fluid flow and heat transfer in plate solar collector channel from natural convection are the conservation of mass, momentum, and energy. (Fluent version 6.2.16 user manual). Flow under consideration and coordinate system is shown in Figure(1).

\section{Continuity Equation:}

$\frac{\partial p}{\partial t}+\frac{\partial(p u)}{\partial x}+\frac{\partial(p v)}{\partial y}+\frac{\partial(p w)}{\partial z}=0$

Momentum Equation in $\mathrm{x}$ direction is:

$\rho\left[\frac{\partial u}{\partial t}+u \frac{\partial u}{\partial x}+v \frac{\partial u}{\partial y}+w \frac{\partial u}{\partial z}\right]=-\frac{\partial p}{\partial x}+\mu\left[\frac{\partial^{2} u}{\partial x^{2}}+\frac{\partial^{2} u}{\partial y^{2}}+\frac{\partial^{2} u}{\partial z^{2}}\right]+\rho g_{x}$

Momentum Equation in y direction is:

$\rho\left[\frac{\partial v}{\partial t}+u \frac{\partial v}{\partial x}+v \frac{\partial v}{\partial y}+w \frac{\partial v}{\partial z}\right]=-\frac{\partial p}{\partial y}+\mu\left[\frac{\partial^{2} v}{\partial x^{2}}+\frac{\partial^{2} v}{\partial y^{2}}+\frac{\partial^{2} v}{\partial z^{2}}\right]+\rho g_{y}$

Momentum Equation in $\mathrm{z}$ direction is:

$\rho\left[\frac{\partial \mathrm{w}}{\partial \mathrm{t}}+\mathrm{u} \frac{\partial \mathrm{w}}{\partial \mathrm{x}}+\mathrm{v} \frac{\partial \mathrm{w}}{\partial \mathrm{y}}+\mathrm{w} \frac{\partial \mathrm{w}}{\partial \mathrm{z}}\right]=-\frac{\partial \mathrm{p}}{\partial z}+\mu\left[\frac{\partial^{\mathrm{s}} \mathrm{w}}{\partial \mathrm{x}^{\mathrm{s}}}+\frac{\partial^{\mathrm{s}} \mathrm{w}}{\partial \mathrm{y}^{\mathrm{s}}}+\frac{\partial^{\mathrm{s}} \mathrm{w}}{\partial \mathrm{z}^{\mathrm{s}}}\right]+\rho \mathrm{g}_{z}$

Energy equation:

$\frac{\partial}{\partial t}(\rho T)+\frac{\partial}{\partial x}(\rho u T)+\frac{\partial}{\partial y}(\rho v T)+\frac{\partial}{\partial z}(\rho w T)=\frac{\partial}{\partial x}\left(k_{\text {eff }} \frac{\partial T}{\partial x}\right)+\frac{\partial}{\partial y}\left(k_{\text {eff }} \frac{\partial \mathrm{T}}{\partial y}\right)+\frac{\partial}{\partial z}\left(k_{\text {eff }} \frac{\partial \mathrm{T}}{\partial z}\right)+\mathrm{S}_{\mathrm{T}}$

where:

$\mathrm{k}_{\mathrm{eff}}$ is effective thermal conductivity $(\mathrm{W} / \mathrm{m} . \mathrm{K})$ calculated as $\mathrm{k}_{\mathrm{eff}}=\gamma \mathrm{k}_{\mathrm{f}}+(1-\gamma) \mathrm{k}_{\mathrm{g}}$ subscript $\mathrm{f}$, and $\mathrm{s}$ hold for fluid and solid respectively

$\mathrm{u}, \mathrm{v}, \mathrm{w}$ components of water velocity within the collector $(\mathrm{m} / \mathrm{s})$

$\mathrm{t}$ is time (s)

\section{Turbulence Model}

The standard $\tilde{K}$ - $\omega$ model is a semi-empirical model based on model transport equations for the turbulence kinetic energy $(\tilde{K})$ and its dissipation rate $(\omega)$ and more appreciate. The model transport equation for $(\tilde{\mathrm{K}})$ is derived from the exact equation, while the model transport equation for $(\omega)$ was obtained using physical reasoning and bears little resemblance to its mathematical exact counterpart.

The turbulence kinetic energy $(\hat{K})$ and it's rate of dissipation $(\omega)$ are obtained from the following transport equations (Collie et. al., 2001):

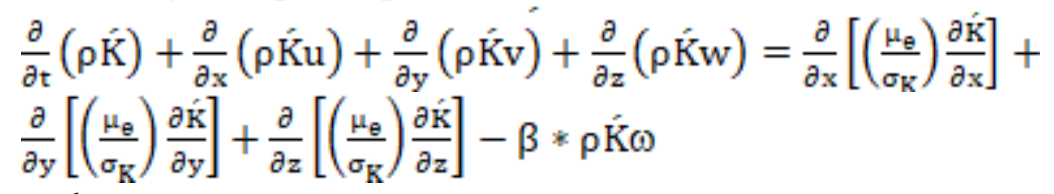

and

$\frac{\partial}{\partial \mathrm{t}}(\rho \omega)+\frac{\partial}{\partial \mathrm{x}}(\rho \omega \mathrm{u})+\frac{\partial}{\partial \mathrm{y}}(\rho \omega \mathrm{v})+\frac{\partial}{\partial \mathrm{z}}(\rho \omega \mathrm{w})=\frac{\partial}{\partial \mathrm{x}}\left[\left(\frac{\mu_{\mathrm{e}}}{\sigma_{\mathrm{m}}}\right) \frac{\partial \omega}{\partial \mathrm{x}}\right]+$

$\frac{\partial}{\partial y}\left[\left(\frac{\mu_{e}}{\sigma_{\omega}}\right)\right]+\frac{\partial}{\partial z}\left[\left(\frac{\mu_{e}}{\sigma_{\omega}}\right) \frac{\partial \omega}{\partial z}\right]+\alpha_{1} \frac{\omega}{K}\left(G_{K}+C_{3 \omega} G_{b}\right)-\beta \rho \omega^{2}$ 
The steady state has been adopted in this case by analyzing the solar collector at solar noon, i.e the transient terms has been ignored in this work

\section{Boundary Conditions}

Referring to Fig. 1, the associated boundary conditions necessary to complete the formulation of the present work are:

\section{Inlet to the collector}

Steady uniform velocity at the collector inlet

$$
\mathrm{x}=0, \quad 18.7 \mathrm{~mm} \leq \mathrm{y} \leq 31.35 \mathrm{~mm}
$$

(where the inlet pipe is located at the center of solar collector thickness which is $50.8 \mathrm{~mm}$ or 2 inches). The inlet temperature is taken from measured data (at solar noon).

\section{Exit of the collector}

At $\mathrm{x}=2.35 \mathrm{~m}$ the pressure is equal to the head difference between the free surface in the storage tank and exit height,

$$
\mathrm{p}=\mathrm{p}_{\mathrm{n}}
$$

and

$\frac{\partial \mathrm{u}}{\partial \mathrm{x}}=\frac{\partial \mathrm{v}}{\partial \mathrm{x}}=\frac{\partial \mathrm{w}}{\partial \mathrm{x}}=\frac{\partial \mathrm{T}_{\mathrm{f}}}{\partial \mathrm{x}}=0$

Along the solid boundaries of the solar collector the no slip conditions are used.

$\mathrm{u}=0, \mathrm{v}=0, \mathrm{w}=0$

Also all sides and back surface of the collector are taken as insulated surfaces such that is

$\frac{\partial T}{\partial n}=0$

where $\mathrm{n}$ is normal unit vector on the surface. The absorber plate is subjected to constant heat flux $\overline{\overline{\mathrm{q}}}$ where

$\frac{\partial T}{\partial n}=\frac{\overline{\bar{q}}}{\mathrm{k}_{\mathrm{abs}}}=\mathrm{I} \tau \alpha$

$\tau \quad$ is the transmissivity of the glass cover.

$\alpha \quad$ is the absorptivity of the absorber.

$k_{a b s}$ is the thermal conductivity of the absorber plate (W/m.K).

\section{EXPERIMENTAL SETUP}

The outdoor test was conducted during the period November and December (2013) in Baghdad. The collector was south oriented at $45^{\circ}$ (For winter load, the tilt angle should be latitude $+10^{\circ}$ and for year round use, the tilt = latitude, Degirmencioglu, 2006). The experiments were carried out from 8:00 AM to 17:00 PM for clear and cloudy days. Fig. 2 shows the general aspect of experimental setup.

Solar collectors are designed to meet the regulations defined on ASHRAE Design Manual Sec3.3. These collectors have been manufactured locally from galvanize plate of dimensions $(0.05 * 0.57 * 1.75 \mathrm{~m})$ and a thickness of $(0.9 \mathrm{~mm})$. Porous media made of multilayer of aluminum mesh is inserted under the absorber plate. The absorber is coated with black mat paint. The collector was thermally insulated from all sides and bottom by glass wool insulation of $(50 \mathrm{~mm})$ thickness to reduce the heat losses. A glass cover $(4 \mathrm{~mm})$ thickness and $\left(1.75^{*} 0.7 \mathrm{~m}\right)$ dimensions is used and sealed to prevent leakage of air. The gap between the glass cover and the absorber plate was $(50 \mathrm{~mm})$ and the porous media depth was $(25 \mathrm{~mm})$. The solar collectors designed, manufactured, and tested are shown in Fig. (4) and Fig. (5).

In this work, the total solar radiation was measured by a digital Data logging solar power meter TES-1333R of accuracy within $\pm 10 \mathrm{~W} / \mathrm{m}^{2}$. The solar meter was south oriented and 
tilted at the same tilt angle of solar collector (i.e. $45^{\circ}$ ). 67 Thermocouples type $\mathrm{k}$ with a range between -200 to $1370{ }^{\circ} \mathrm{C}$ and accuracy of $\pm(0.1 \mathrm{~K} \pm \% 0.05$ of measured value $)$ was used in this work. These thermocouples are connected to three digital temperature reader types (BTM-4208SD) thermometer of 12 channels with data recorder.Water inlet and outlet temperatures, back plate, porous media, absorber plate, glazing cover of the collector and ambient temperatures have been measured as shown in Fig. (6 a, b and c) for collector model (I), (II) and (III) respectively. All data have been recorded every 10 minutes.

\section{Data processing}

The following simplified steps were used to analyze the thermal characteristics of the solar collectors based on the experimental measurement. The absorbed energy by the absorber plate could be calculated by the equation below (Duffie and Beckman, 2013):

$\mathrm{Q}_{\mathrm{ab}}=\mathrm{F}_{\mathrm{t}} * \mathrm{I}_{\mathrm{t}} * \mathrm{~A}$

where, $I_{t}$ is the total incident radiation. The effective transmittance-absorption factor $\left(F_{t}\right)$ is calculated from the following equation:

$\mathrm{F}_{\mathrm{t}}=\left(\alpha_{\mathrm{p}} \tau_{\mathrm{g}}\right)_{\mathrm{e}} * \mathrm{~F}_{\mathrm{sh}} * \mathrm{~F}_{\mathrm{d}}$

where;

$\mathrm{F}_{\mathrm{sh}}$ Shading coefficient.

$\mathrm{F}_{\mathrm{d}}$ Dust coefficient.

$\left(\alpha_{\mathrm{p}} \tau_{\mathrm{g}}\right)_{\mathrm{e}}$ Is calculated as follows:

$\left(\alpha_{\mathrm{p}} \tau_{\mathrm{g}}\right)_{\mathrm{e}}=1.02 * \alpha_{\mathrm{p}} \tau_{\mathrm{g}}$

The energy loss from solar collector is given by:

$\mathrm{Q}_{\text {loss }}=\mathrm{U}_{\mathrm{l}} * \mathrm{~A} *\left(\mathrm{~T}_{\mathrm{p}}-\mathrm{T}_{\mathrm{a}}\right)$

Mean plate temperature $\left(T_{p}\right)$ is calculated as follows (Duffie and Beckman, 2013):

$\mathrm{T}_{\mathrm{p}}=\mathrm{T}_{\mathrm{i}}+\frac{\mathrm{Q}_{\mathrm{u}} / \mathrm{A}}{\mathrm{F}_{\mathrm{R}} \mathrm{U}_{\mathrm{I}}}\left(1-\mathrm{F}_{\mathrm{R}}\right)$

The heat removal factor $\left(F_{R}\right)$ is given as:

$\mathrm{F}_{\mathrm{R}}=\mathrm{F}^{\mathrm{I}} \mathrm{F}^{\prime}$

where the collector flow factor $\mathrm{F}^{\prime \prime}$ and the collector efficiency factor $\mathrm{F}^{\prime}$ are calculated as follows:

$$
\begin{aligned}
& \mathrm{F}^{\prime \prime}=\frac{\mathfrak{\mathrm { m }}_{\mathrm{W}} \mathrm{c}_{\mathrm{p}}}{\mathrm{AU}_{\mathrm{l}} \mathrm{F}^{t}}\left[1-\exp \left(-\frac{\mathrm{AU}_{\mathrm{l}} \mathrm{F}^{\mathrm{w}}}{\mathrm{m}_{\mathrm{W}} \mathrm{c}_{\mathrm{p}}}\right)\right] \\
& \mathrm{F}^{\mathrm{n}}=\frac{\mathrm{m}_{\mathrm{W}} \mathrm{c}_{\mathrm{p}}}{\mathrm{AU}_{\mathrm{l}} \mathrm{F}^{\mathrm{F}}}\left[1-\exp \left(-\frac{\mathrm{AU}_{1} \mathrm{~F}}{\mathrm{~m}_{\mathrm{W}} \mathrm{c}_{\mathrm{p}}}\right)\right] \\
& \mathrm{F}^{o}=\left[1+\frac{\mathrm{U}_{\mathrm{l}}}{\mathrm{h}+\left(\frac{1}{\mathrm{~h}}+\frac{1}{\mathrm{~h}_{\mathrm{r}}}\right)^{-1}}\right]^{-1} \\
& \mathrm{~h}_{\mathrm{r}}=\frac{4 \sigma \mathrm{T}_{\mathrm{mf}}^{\mathrm{g}}}{\frac{1}{\mathrm{~s}_{\mathrm{p}}}+\frac{1}{\varepsilon_{\mathrm{g}}}-1}
\end{aligned}
$$

where the mean fluid temperature $\left(\mathrm{T}_{\mathrm{mff}}\right)$ is calculated from the following equation:

$$
\begin{aligned}
& \mathrm{T}_{\mathrm{mf}}=\frac{\mathrm{T}_{\mathrm{p}}+\mathrm{T}_{\mathrm{g}}}{2} \\
& \mathrm{~h}=\mathrm{Nu} \frac{\mathrm{K}}{\mathrm{D}_{\mathrm{hh}}} \\
& \mathrm{Ra}=\frac{\mathrm{gB}^{2} \Delta \mathrm{TL} \mathrm{L}^{\mathrm{g}}}{\mathrm{ve}} \\
& \mathrm{Nu}=1+1.44\left[1-\frac{1708(\sin 1.8 \beta)^{1.6}}{\mathrm{Ra} \cos \beta}\right]\left[1-\frac{1708}{\mathrm{Ra} \cos \beta}\right]^{+}+\left[\left(\frac{\mathrm{Racos} \beta}{5830}\right)^{\frac{1}{\mathrm{a}}}-1\right]^{+}
\end{aligned}
$$

The collector overall heat transfer coefficient $\left(\mathrm{U}_{1}\right)$ is the sum of top, bottom and edge 
loss coefficients:

$\mathrm{U}_{\mathrm{l}}=\mathrm{U}_{\mathrm{t}}+\mathrm{U}_{\mathrm{b}}+\mathrm{U}_{\mathrm{e}}$

The back loss coefficient is found from:

$\mathrm{U}_{\mathrm{b}}=\frac{\mathrm{K}_{\mathrm{b}}}{\mathrm{x}_{\mathrm{b}}}$

The edge loss coefficient based on the collector area is found as:

$\mathrm{U}_{\mathrm{e}}=\frac{\mathrm{K}_{\mathrm{e}}}{\mathrm{X}_{\mathrm{\alpha}}} \cdot \frac{\mathrm{A}_{\mathrm{e}}}{\mathrm{A}}$

where the edge area is the product of the perimeter of the collector by the collector thickness.

The top loss coefficient from the collector plate to the ambient for this single glass cover system is as follows:

$\mathrm{U}_{\mathrm{t}}=\left[\frac{1}{\mathrm{~h}_{\mathrm{e}, \mathrm{p}-\mathrm{g}}+\mathrm{h}_{\mathrm{r}, \mathrm{p}-\mathrm{g}}}+\frac{1}{\mathrm{~h}_{\mathrm{W}}+\mathrm{h}_{\mathrm{r}, \mathrm{R}-\mathrm{g}}}\right]^{-1}$

The convective heat transfer coefficient $\left(h_{\mathrm{w}}\right)$ is calculated based on wind speed (v) (Duffie and Beckman, 2013):

$\mathrm{h}_{\mathrm{w}}=5.7+3.8 \mathrm{v}$

The radiation heat transfer coefficient from the glass to the ambient $\left(\mathrm{h}_{\mathrm{r}, \mathrm{g}-\mathrm{a}}\right)$ is calculated as:

$\mathrm{h}_{\mathrm{r}_{\mathrm{g}}-\mathrm{a}}=\varepsilon_{\mathrm{g}} \sigma\left(\mathrm{T}_{\mathrm{g}}+\mathrm{T}_{\mathrm{s}}\right)\left(\mathrm{T}_{\mathrm{g}}^{2}+\mathrm{T}_{\mathrm{s}}^{2}\right)$

where $\left(T_{g}\right)$ is sky temperature (in this work $\left(T_{g}\right)$ is taken equal to ambient temperature).

The radiation heat transfer coefficient from the plate to the glass cover $\left(\mathrm{h}_{\mathrm{r}, \mathrm{p}-\mathrm{g}}\right)$ is calculated as:

$\mathrm{h}_{\mathrm{r}, \mathrm{p}-\mathrm{g}}=\frac{\sigma\left(\mathrm{T}_{\mathrm{p}}+\mathrm{T}_{\mathrm{g}}\right)\left(\mathrm{T}_{\mathrm{p}}^{\mathrm{a}}+\mathrm{T}_{\mathrm{g}}^{\mathrm{a}}\right)}{\frac{1}{\varepsilon_{\mathrm{p}}}+\frac{1}{\varepsilon_{g}}-1}$

The convective heat transfer coefficient is calculated as:

$h_{c, p-g}=\frac{N u K}{D_{h}}$

where $\left(D_{h}\right)$ is the equivalent (hydraulic) diameter of the duct. In the case with porous media $\left(D_{h}\right)$ is given by (ASHRAE solar design manual, 1980):

$D_{h}=\varepsilon \frac{2 W d}{W+d}$

where $\varepsilon$ is the porosity of the porous medium, $w$ is the width of the duct and $d$ is the depth of the duct.

Nusselt number $\mathrm{Nu}$ for the air gap below the glass cover is a function of Rayleigh number Ra which is given by (Duffie and Beckman, 2013):

$N u=1+1.44\left[1-\frac{1708(\sin 1.8 \beta)^{1.6}}{R a \cos \beta}\right]\left[1-\frac{1708}{R a \cos \beta}\right]^{+}+\left[\left(\frac{R a \cos \beta}{5830}\right)^{\frac{1}{3}}-1\right]^{+}$

"The (+) sign indicates that only the positive value taken into account"

Rayliegh number is calculated as:

$\operatorname{Ra}=\frac{\mathrm{g}^{2}\left(\mathrm{~T}_{\mathrm{p}}-\mathrm{T}_{\mathrm{g}}\right) \xi^{\mathrm{a}}}{\text { va. }}$

where $\xi$ is the space between the glass cover and the absorber plate. The properties of air are evaluated at the ambient $\left(\mathrm{T}_{\mathrm{a}}\right)$.

$\left(v=\frac{\mu}{\rho} ; \alpha=\frac{\mathrm{K}}{\rho \mathrm{c}_{\mathrm{p}}}\right)$ 
The useful heat gain $\mathrm{Q}_{\mathrm{u}}$ of the solar collector is calculated as follow:

$\mathrm{Q}_{\mathrm{u}}=\mathrm{F}_{\mathrm{R}} \mathrm{A}\left[\mathrm{S}-\mathrm{U}_{\mathrm{l}}\left(\mathrm{T}_{\mathrm{i}}-\mathrm{T}_{\mathrm{a}}\right)\right]$

which can be calculated as:

$\mathrm{Q}_{\mathrm{u}}=\mathrm{m}_{\mathrm{w}} * \mathrm{c}_{\mathrm{p}} *\left(\mathrm{~T}_{\mathrm{o}}-\mathrm{T}_{\mathrm{i}}\right)$

or the outlet temperature is evaluated as:

$\mathrm{T}_{\mathrm{o}}=\mathrm{T}_{\mathrm{i}}+\mathrm{Q}_{\mathrm{u}} / \mathrm{m}_{\mathrm{w}}^{*} * \mathrm{c}_{\mathrm{p}}$

The thermal efficiency of the flat-plate solar collector $\left(\eta_{r}\right)$ is define as the ratio of the rate of useful energy supplied by the collector $\left(Q_{u}\right)$ to the rate of incident solar energy in its area.

$\eta_{\mathrm{c}}=\frac{\mathrm{Q}_{\mathrm{u}}}{\mathrm{I}_{\mathrm{t}} \mathrm{A}_{\mathrm{T}}}$

The incident solar energy on the solar collector area is found by multiplying the total solar intensity (which is found experimentally) by the collector area.

\section{RESULTS AND DISCUSSIONS Experimental Results}

Outdoor tests from November 2013 to April 2014 in Baghdad are conducted. The test extended (from 6:00 am to 5:00 pm) for clear days. Figure (7) shows the variation of the hourly measured solar radiation, ambient temperature and wind speed on clear day $\left(14^{\text {th }}\right.$ Nov. 2013). The intensity of solar radiation increases steadily with time and reaches its peak value at the mid-day (was $782.189 \mathrm{~W} / \mathrm{m}^{2}$ ) then decreases steadily towards sunset . The maximum air temperature was $\left(22.4^{\circ} \mathrm{C}\right)$, while the wind speed was varied from $8 \mathrm{~km} / \mathrm{hr}(2.22 \mathrm{~m} / \mathrm{s})$ to $10 \mathrm{~km} / \mathrm{hr}(2.78 \mathrm{~m} / \mathrm{s})$. Figure (8) shows the variation of measured water inlet and outlet temperature to and from the collector with time on (14th Nov. 2013) for the three types of collectors. The water outlet temperature from collector at solar noon was $\left(35.2^{\circ} \mathrm{C}\right)$ for model (I), $\left(40.6^{\circ} \mathrm{C}\right)$ for model (II) and $\left(43.1^{\circ} \mathrm{C}\right)$ for model (III) on (14th Nov.2013). The temperature difference reached the maximum value between $(1: 30$ th to $2: 00 \mathrm{pm})$ then it decreased with time following the solar radiation. Figure (9) shows the variation of calculated useful energy gain with solar radiation at solar noon for collector model (I), (II) and (III). The maximum useful energy was recorded for model (III). For incident solar radiation of $1016 \mathrm{~W} / \mathrm{m}^{2}$ the useful heat gain was $525.7 \mathrm{~W}$ for model III, was $495.3 \mathrm{~W}$ for model (II), while for model (I) was $425.83 \mathrm{~W}$. Figure (10) presents the collector thermal efficiency with no water withdrawal from the system. The collector maximum efficiency was $52.22 \%$ for model (III) (on $1^{\text {st }}$ Dec. 2013 ) at solar noon, $49.2 \%$ for model (II), and $42.3 \%$ for model (I).

Figure (11) shows the Variation of total heat loss coefficient with $\left(\mathrm{T}_{\mathrm{p}}-\mathrm{T}_{\mathrm{a}}\right)$ at solar noon for the three models (I, II, and III) (2013). Inconsiderable difference in the value of $U_{t}$ is found between the three tested models, with maximum heat loss coefficient is reported on ( $1^{\text {st }}$ Dec. 2013). Figure (12) shows the variation heat removal factor with solar radiation at solar noon. The maximum heat removal factor was $0.9366\left(\mathrm{~W} / \mathrm{m}^{2} .{ }^{\circ} \mathrm{K}\right)$ for model (III) on $\left(1^{\text {st }}\right.$ Dec. 2013). Figure (13) shows the variation of mass flow rate with solar radiation at solar noon for the models (I), (II) and (III) on $\left(13^{\text {th }}, 14^{\text {th }}, 27^{\text {th }}\right.$ and $30^{\text {th }}$ Nov. and $1^{\text {st }}$ Dec. 2013). We note that maximum mass flow rate was $0.012(\mathrm{~kg} / \mathrm{s})$ in model (I) on $\left(1^{\text {st }}\right.$ Dec. 2013).

\section{Computational Results}

Figure (14) shows the distribution of temperature contours resulted from the adopted computational algorithm for the absorber of the studied three collector models. A clear 
temperature rise is shown along the collector for the three models, but model (III) reveals best distribution of temperature compared with model (I) and model (II) because of the existence of corrugated sides for the ducts which affect the fluid velocity within each channel as it is proceed in its movement toward the exit.

\section{CONCLUSIONS}

The conclusions can be drawn from the present work that porous media which placed into the flat plate solar collector as a heat absorber has a positive effect on collector efficiency, the variation of water temperature difference between inlet and outlet of the solar collector with time was higher in model (II) and (III) than (I). Highest values of useful heat gain were found for model (III). Highest thermal efficiency of solar collector model III was obtained compared to that models (I, and II). The mass flow rate in model (III) was the highest. Inconsiderable difference in total heat loss coefficient is indicated for the three tested models. More uniform temperature distribution for model (III) is found computationally compared with that for models (II, and I).

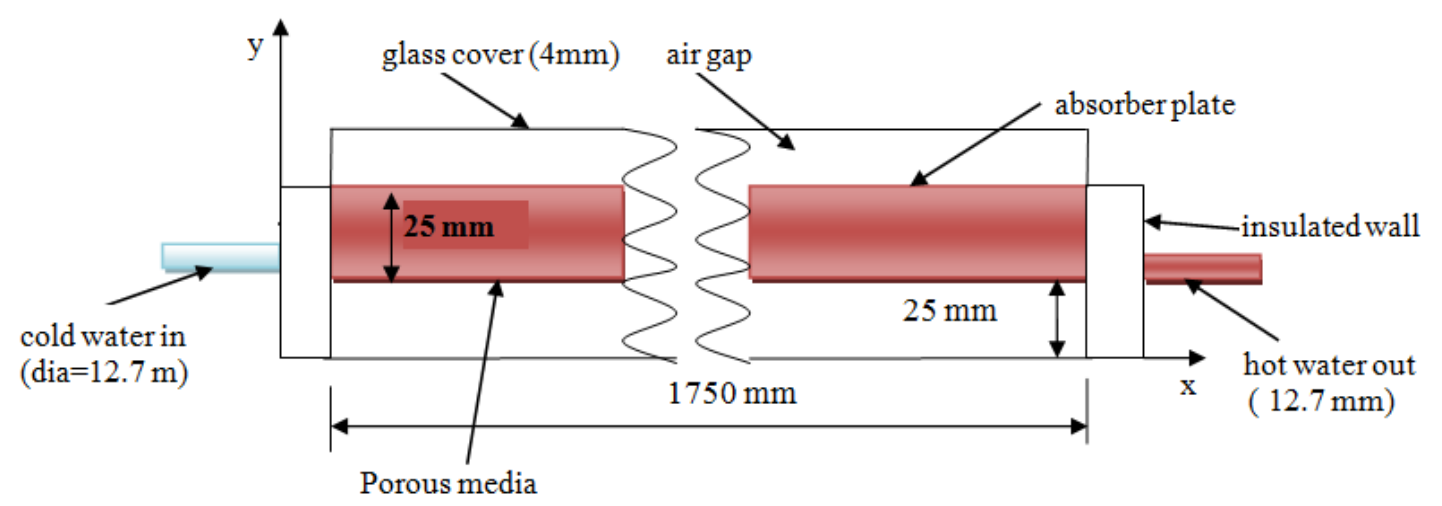

Fig.(1): Schematic diagram of the solar collector inserted with porous media

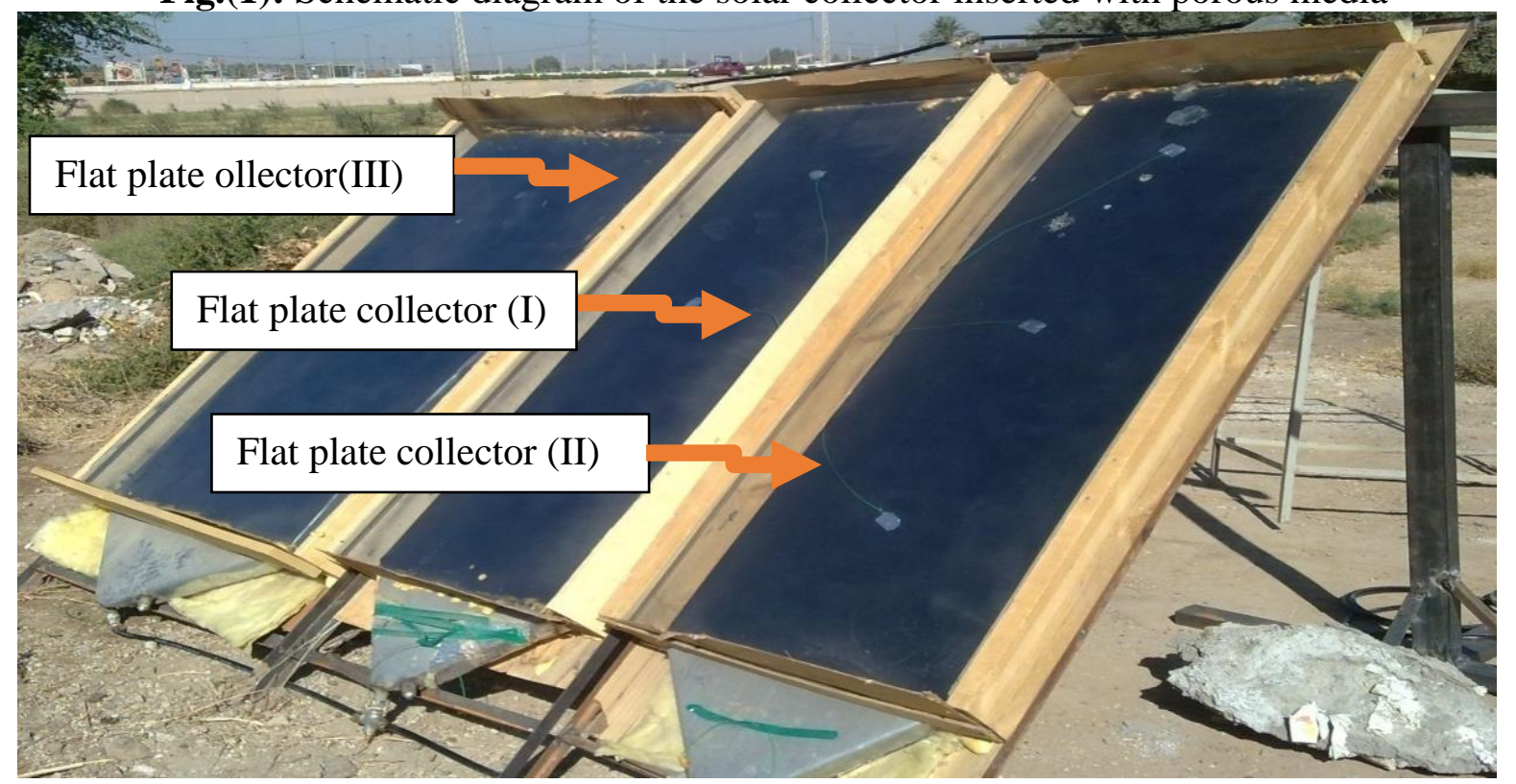

Figure (2) General Aspect of Experimental Setup. 


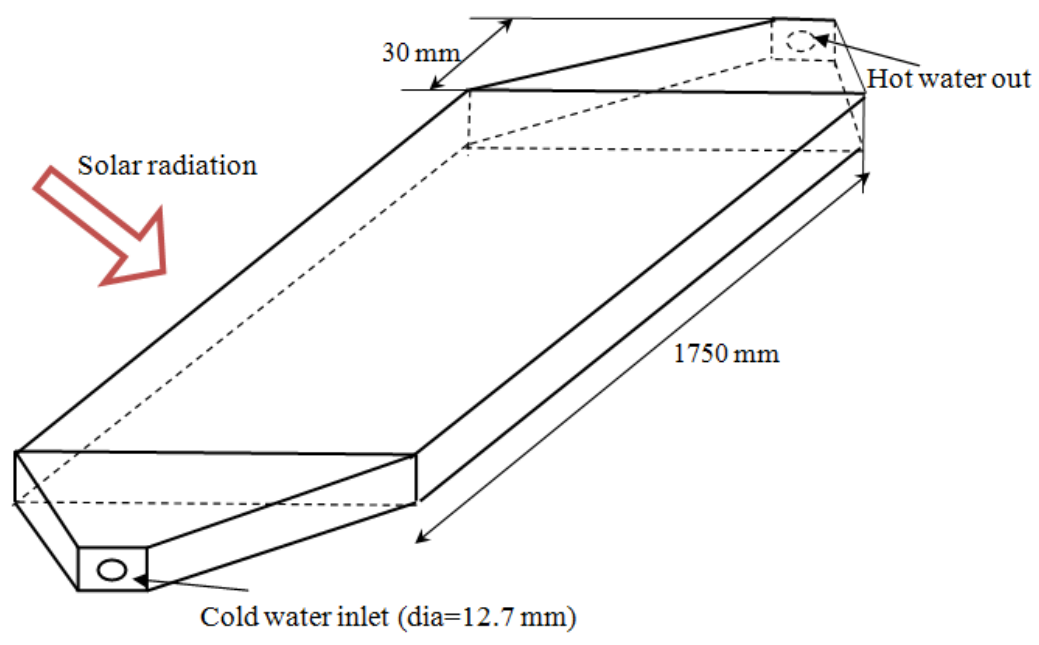

Fig.(3): Schematic model of the Solar Collector

(a)

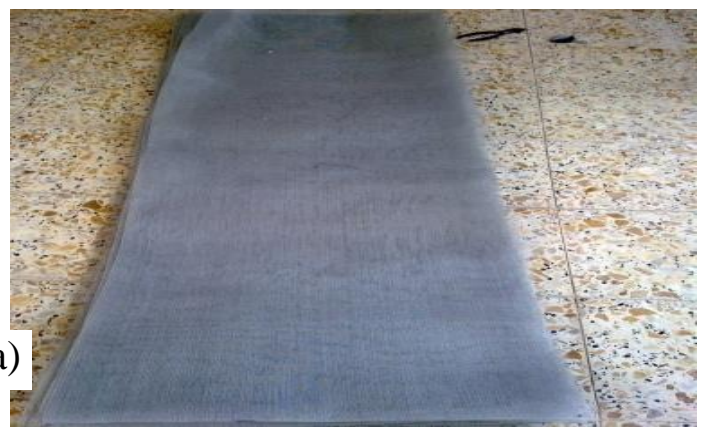

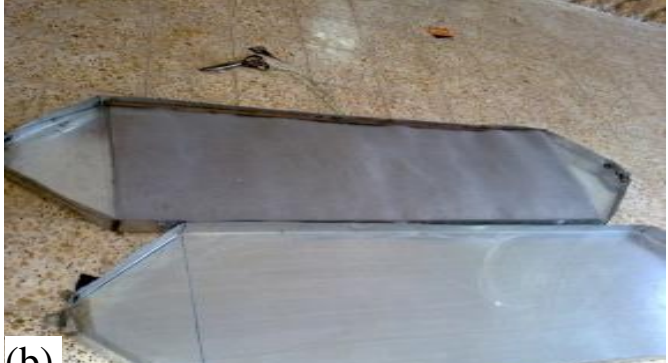

(b)

Fig.(4): Solar Collector Model II, a) Porous media ; b)collector.
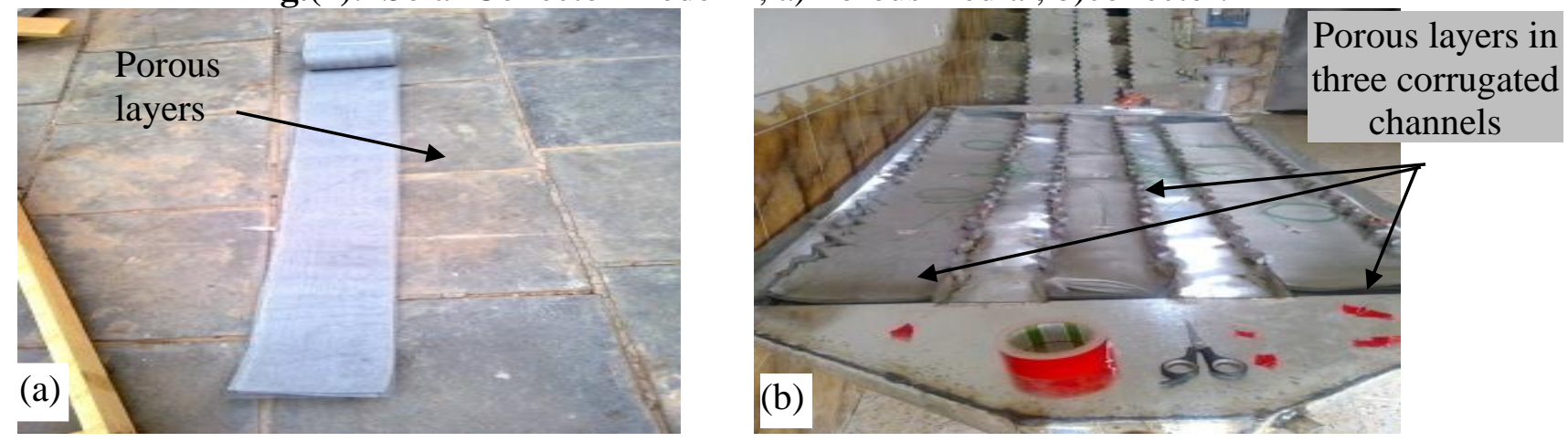

Fig.(5): a)Porous media to be inserted below the absorber ; b) Corrugated channels of solar collector model (III). 


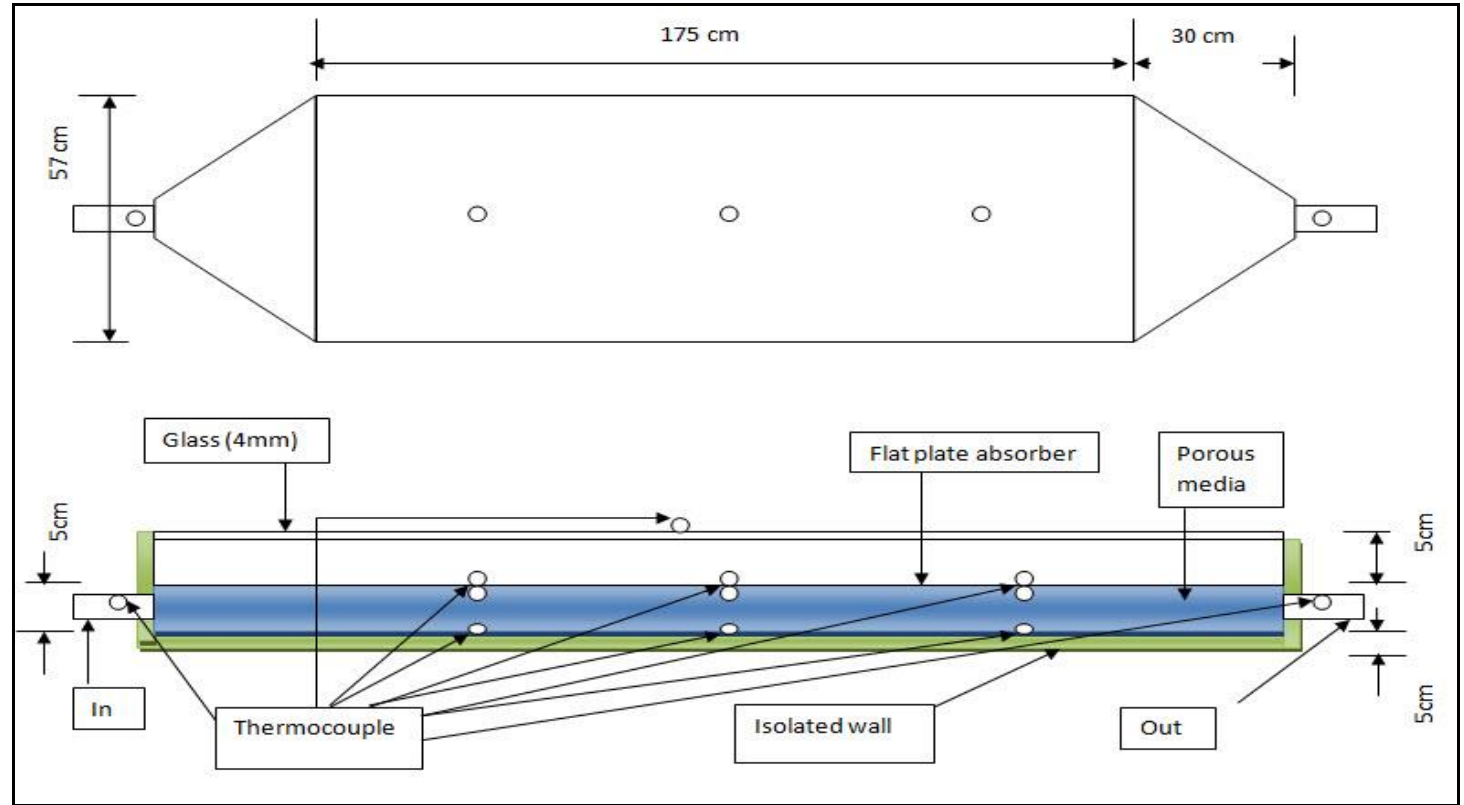

(a)
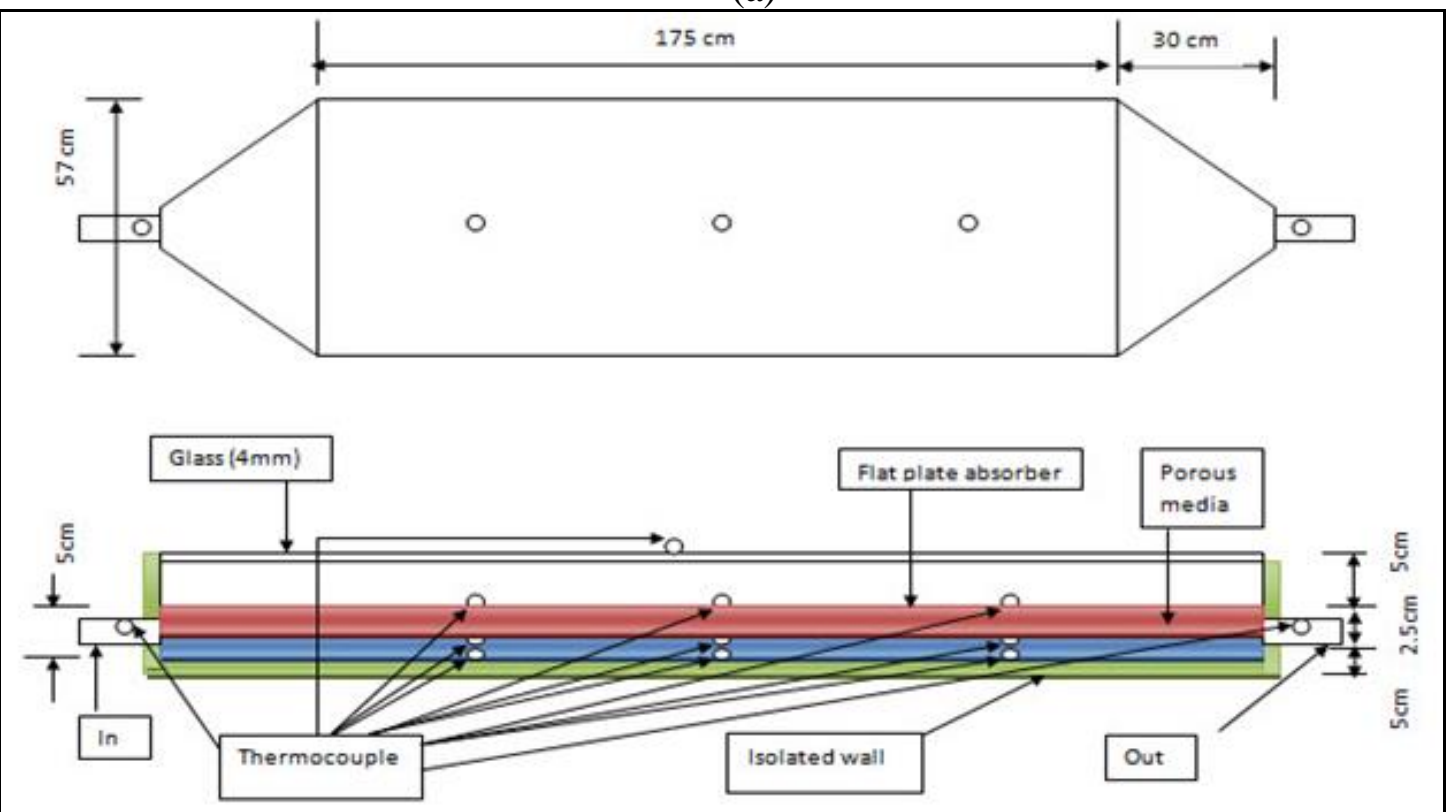

(b)

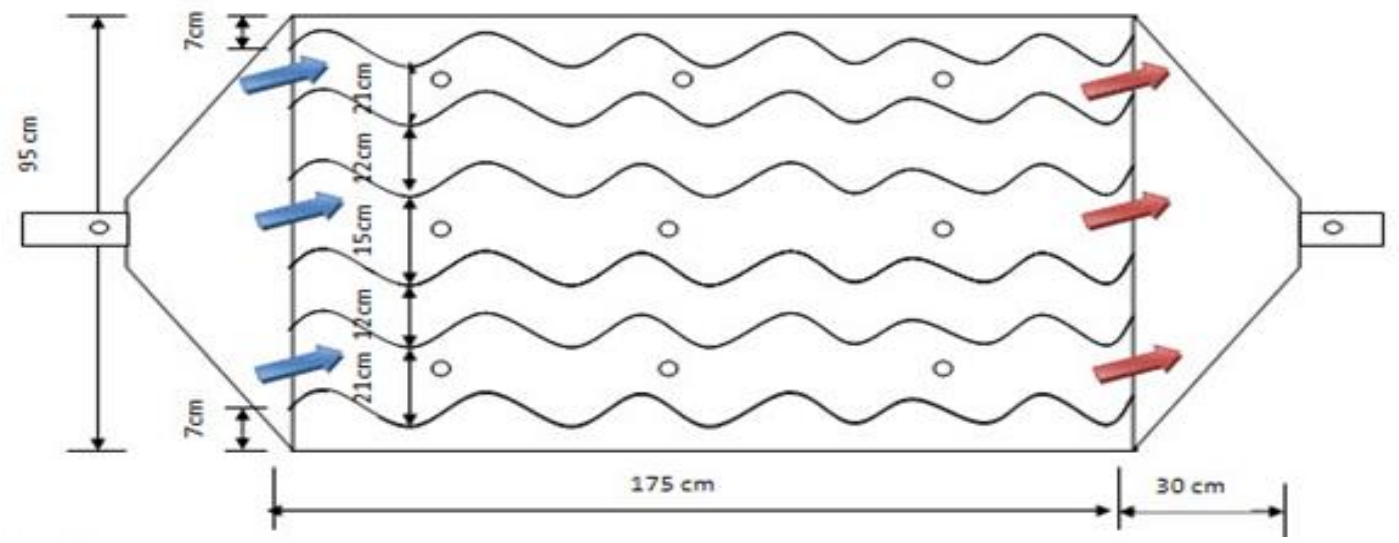

(c)

Fig. (6): Schematic diagram of the tested solar collectors a) model I. b) model II. c) model III. 


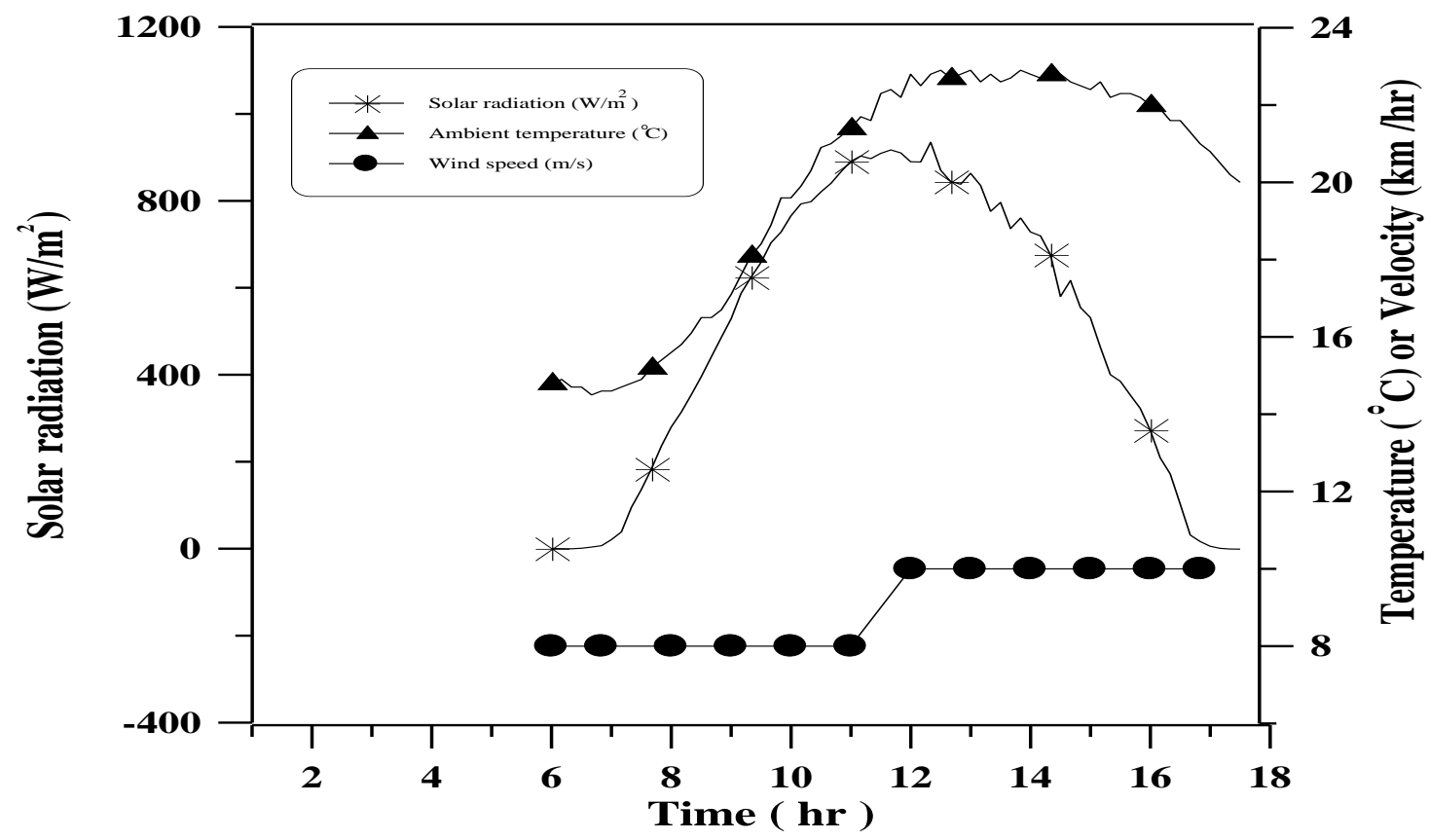

Fig. (7): Variation of measured solar radiation, ambient temperature and wind speed with time $\left(14^{\text {th }}\right.$ Nov. 2013).

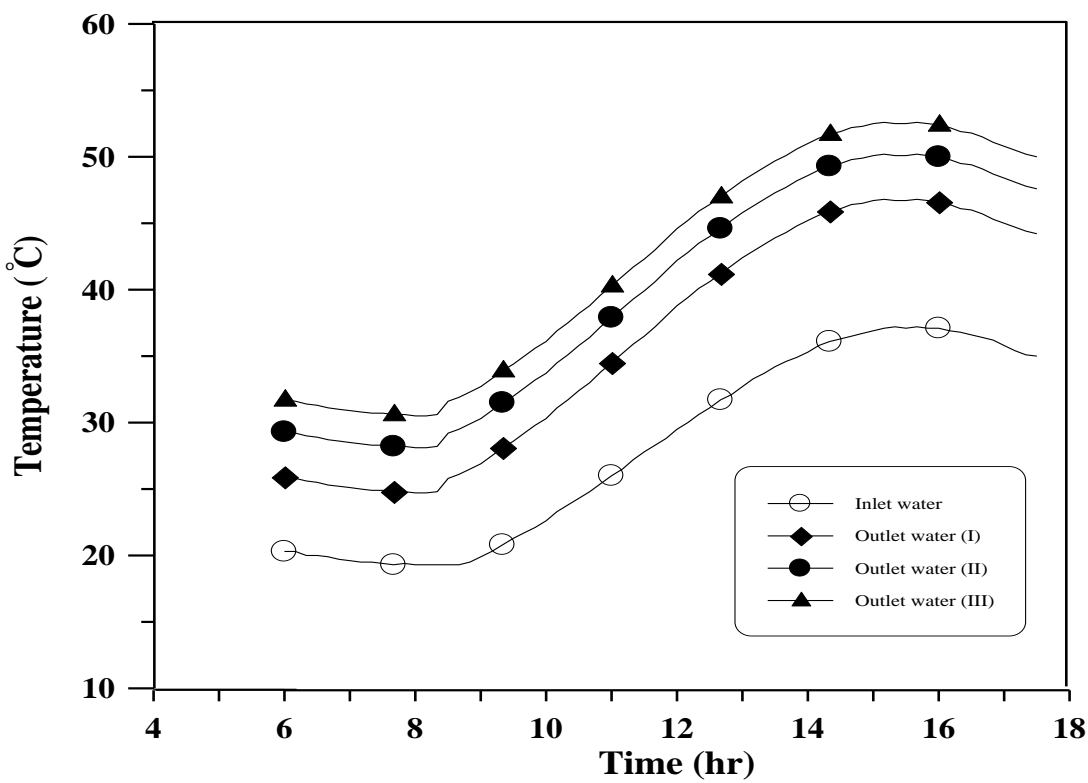

Fig.(8): Variation of inlet and outlet temperature with time for collectors (I), (II) and (III) (14 ${ }^{\text {th }}$ Nov. 2013). 


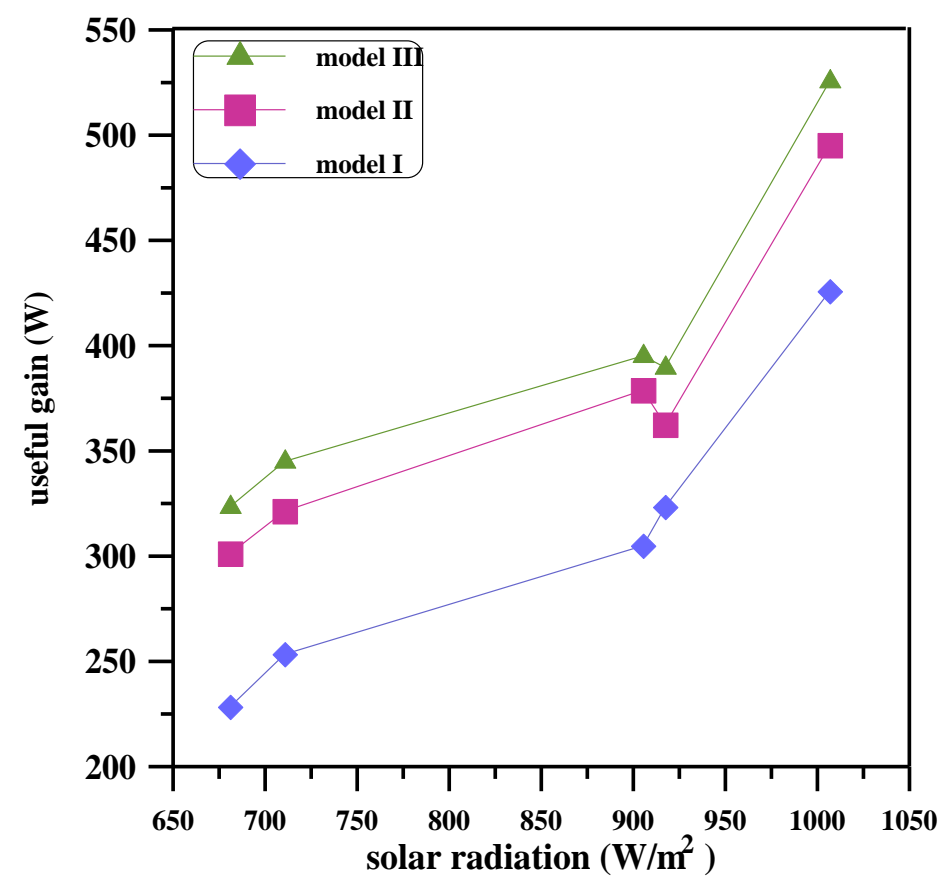

Fig. (9): Variation of useful energy with solar radiation at solar noon for three models (I), (II) and (III) during five clear sky days

(13th, 14th, 27th and 30th Nov. and 1st Dec. 2013)(Exp.)

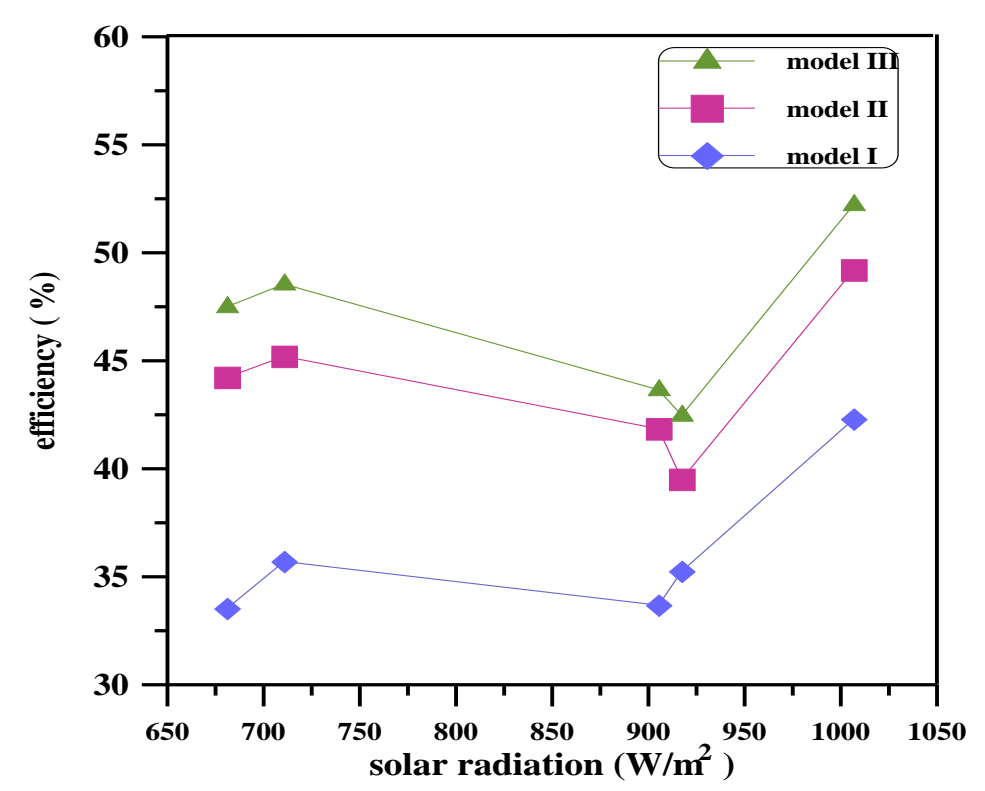

Fig.(10): Variation of experimental efficiency with solar radiation at solar noon for models (I), (II) and (III) (2013) (exp.). 


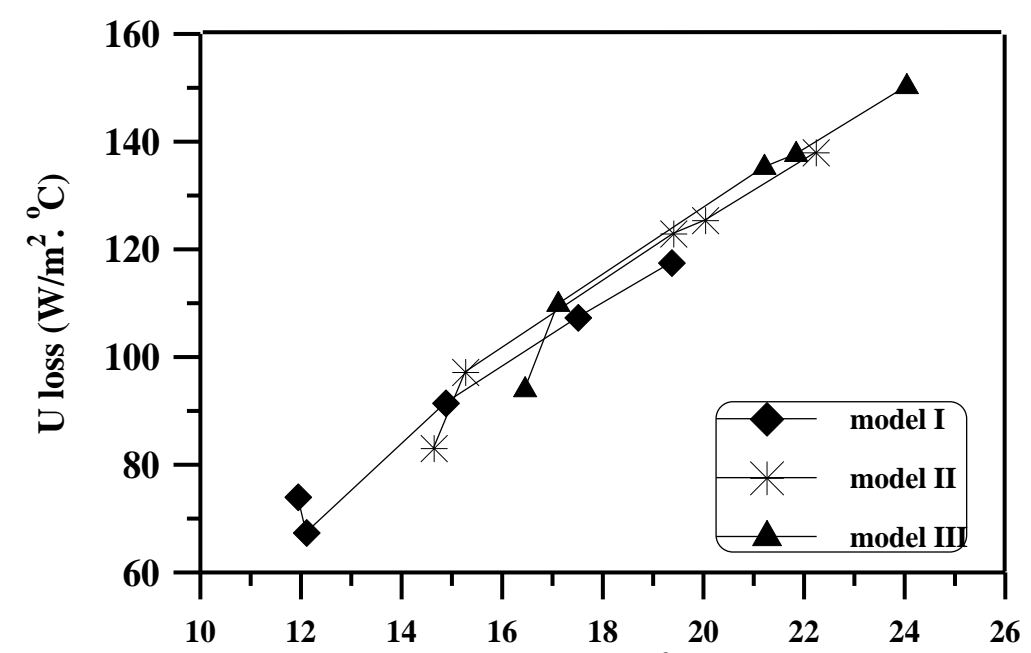

(Tp- Ta) ${ }^{\circ} \mathrm{C}$

Fig.(11): Variation of total heat loss coefficient with $\left(\mathrm{T}_{\mathrm{p}}-\mathrm{T}_{\mathrm{a}}\right)$ at solar noon for models (I, II and III) (2013). (exp.)

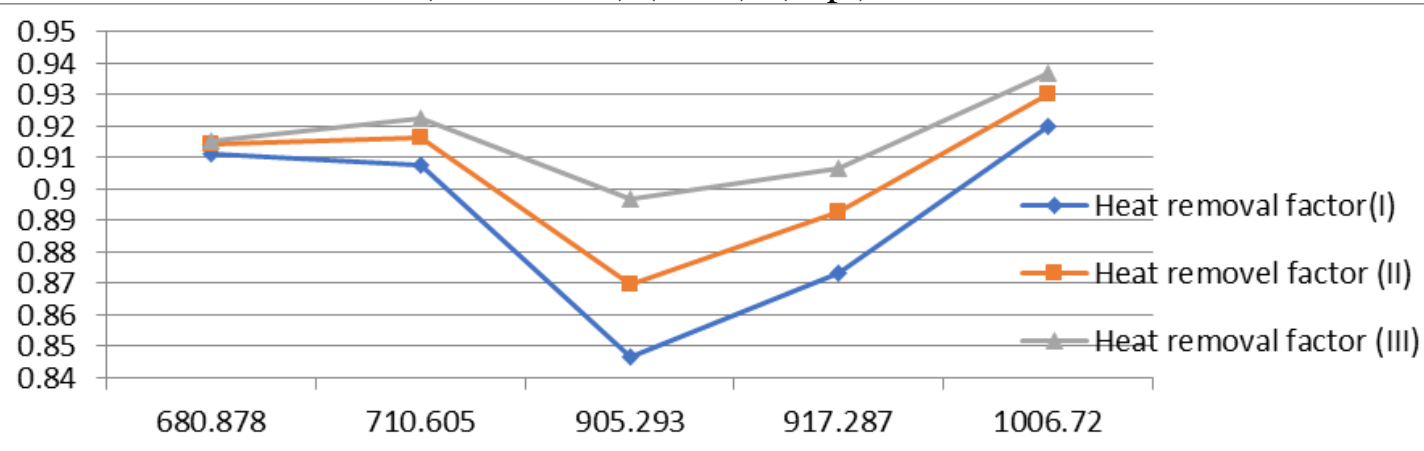

Fig.(12): Variation of Heat removal factor with radiation at solar noon for models (I), (II) and (III)

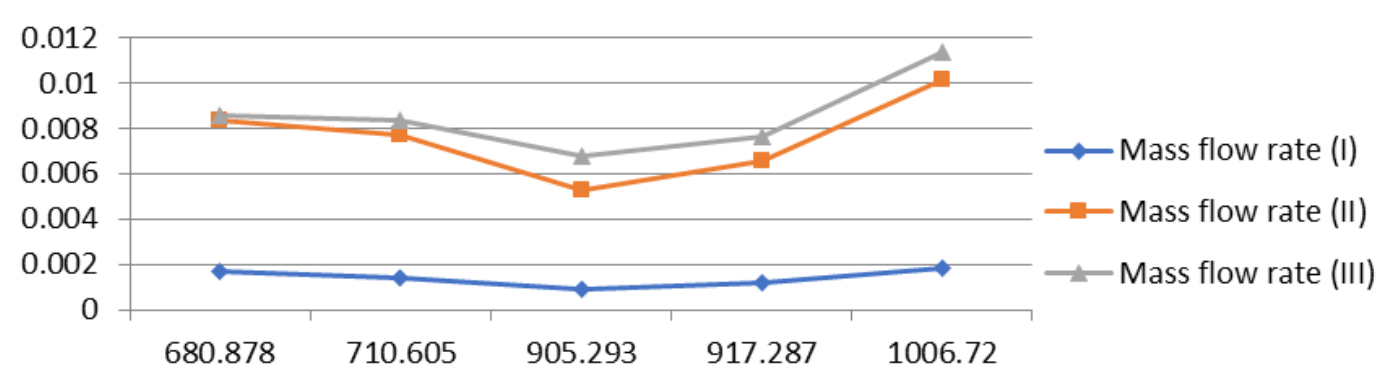

Fig.(13): Variation of mass flow rate with solar radiation at solar noon for models I, II and III (2013) 

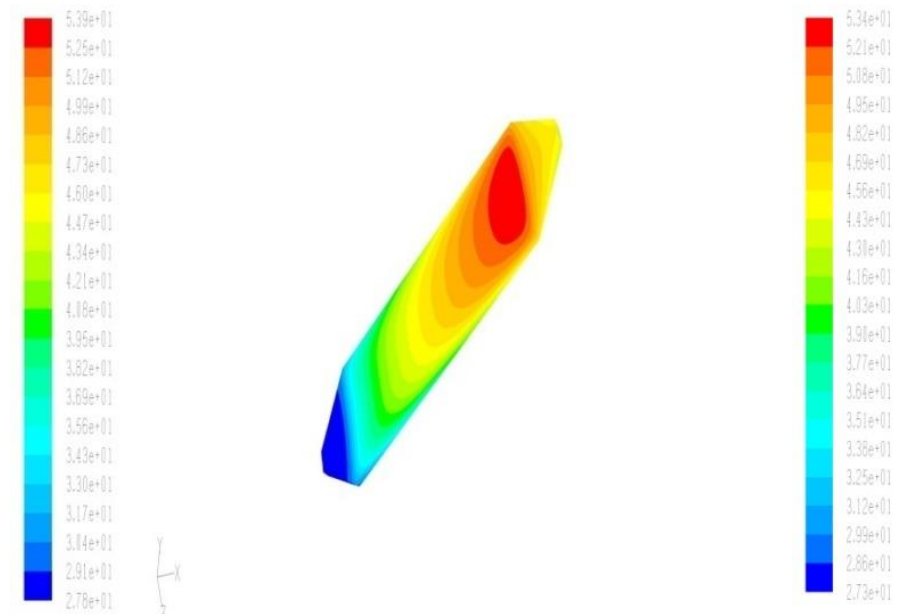

model (I)

model (II)
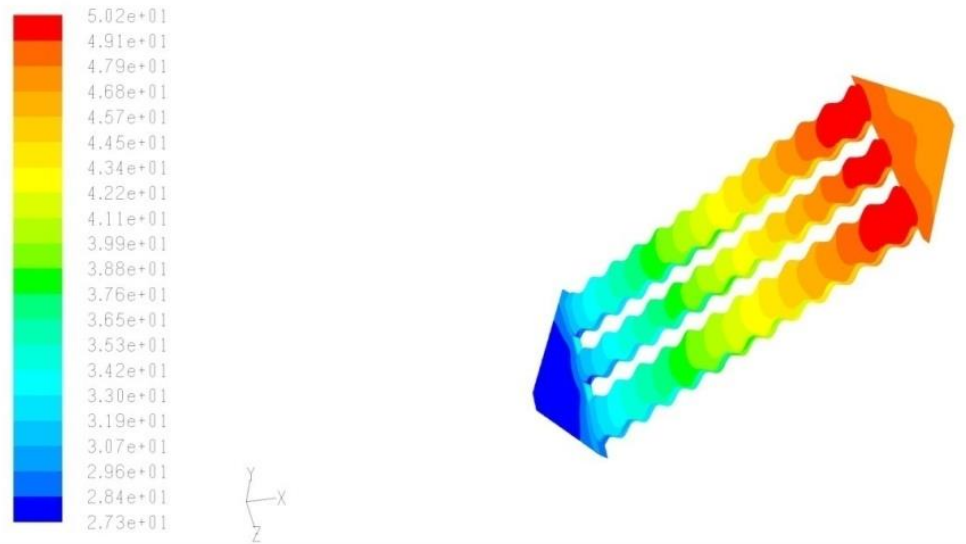

model (III)

Fig. (14): Computed temperature distribution within collector for the three models (I), (II) and (III) on (14 ${ }^{\text {th }}$ Nov. 2013).

\section{REFERENCES}

ASHRAE handbook of Collector Subsystem Design (L/D) (1980).

Chen W. and Liu W., "Numerical analysis of heat transfer in a composite wall solar collector system with a porous absorber", Applied energy (2004) 78:137-149.

Chiou J.P. "The effect of no uniform fluid flow distribution on the thermal performance of solar collector", Solar energy; 29 (6): 487-502(1982).

Chow TT, Chan ALS, Fong KF, Lin Z, He W, Ji J., "Annual performance of building integrated photovoltaic/water-heating system for warm climate application", Appl. Energy ;86:689-96 (2009).

Collie S.J., M. Gerritsen and P. Jackson, 2001, A Review of Turbulence Modelling for use in Sail Flow Analysis, Department of Engineering Science University of Auckland Private Bag 92019 Auckland New Zealand. 
Degirmencioglu, C., The use of open cell polyurethane foams in air-type solar collectors as the heat absorbing element. M.Sc. Thesis, the Graduate School of Engineering and Sciences of İzmir Institute of Technology, (2006).

Duffie, J.A. and Beckman, W.A., Solar Engineering and Thermal Process, John Wiley and Sons, New York, (2013).

Fluent version 6.2.16 user manual .

Hasab M. A., Sorour M. M., "An optimum performance of flat type solar air headed with porous absorber”, Int. J. of energy research, (1987), V.11, 479-489.

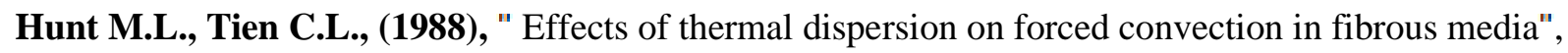
Int. J. Heat Mass Transfer;31:301-308.

Motte F, Notton G, Cristofari C, Canaletti JL., "A building integrated solar collector: performances characterization and first stage of numerical calculation", Renew Energy; 49:15(2013).

Sekhar Y. Raja, Sharma K. V., Basaveswara Rao M.," Evaluation of heat loss coefficients in solar flat plate collectors ", Kukatpally, Hyderabad, India Department of Mechanical Engineering, V.4(5), July (2009).

Suarez I, Prieto MM, Fernandez FJ., "Analysis of potential energy, economic and environmental savings in residential buildings: solar collectors combined with micro-turbines", Appl. Energy;104:128-36,( 2009).

Shariah A.M. , Rousan A., Rousan Kh.K. , Ahmad A.A., "Effect of Thermal Conductivity of Absorber Plate on the Performance of a Solar Water Heater", Applied Thermal Engineering; 19:733741, (1999).

Yousef, "Performance analysis for flat plate collector with and without porous media" Alternative and Renewable Energy Laboratory, Institute of Advanced Technology, Universiti Putra Malaysia, Serdang, Malaysia (2008).

Zerrouki A., Boume'dien A., Bouhadef K., "The natural circulation solar water heater model with linear temperature distribution", Renewable Energy; 26:549-559,(2002).

Zhao, D.L., Li Y., Dai, Y.J. and Wang, R.Z., Optimal study of a solar air heating system with pebble bed energy storage. Energy Conversion and Management; 52(6): 2392-2400, (2011). 